\title{
Acetylcholinesterase inhibition ameliorates deficits in motivational drive
}

\author{
Keri Martinowich ${ }^{1,3^{*}}$, Kathleen M Cardinale ${ }^{1}$, Robert J Schloesser ${ }^{1}$, Michael Hsu', Nigel H Greig ${ }^{2}$ and \\ Husseini K Manji ${ }^{4}$
}

\begin{abstract}
Background: Apathy is frequently observed in numerous neurological disorders, including Alzheimer's and Parkinson's, as well as neuropsychiatric disorders including schizophrenia. Apathy is defined as a lack of motivation characterized by diminished goal-oriented behavior and self-initiated activity. This study evaluated a chronic restraint stress (CRS) protocol in modeling apathetic behavior, and determined whether administration of an anticholinesterase had utility in attenuating CRS-induced phenotypes.
\end{abstract}

Methods: We assessed behavior as well as regional neuronal activity patterns using FosB immunohistochemistry after exposure to CRS for $6 \mathrm{~h} / \mathrm{d}$ for a minimum of $21 \mathrm{~d}$. Based on our FosB findings and recent clinical trials, we administered an anticholinesterase to evaluate attenuation of CRS-induced phenotypes.

Results: CRS resulted in behaviors that reflect motivational loss and diminished emotional responsiveness. CRSexposed mice showed differences in FosB accumulation, including changes in the cholinergic basal forebrain system. Facilitating cholinergic signaling ameliorated CRS-induced deficits in initiation and motivational drive and rescued immediate early gene activation in the medial septum and nucleus accumbens.

Conclusions: Some CRS protocols may be useful for studying deficits in motivation and apathetic behavior. Amelioration of CRS-induced behaviors with an anticholinesterase supports a role for the cholinergic system in remediation of deficits in motivational drive.

Keywords: Apathy, Motivation, Chronic stress, Cholinergic, FosB, c-fos, Nucleus accumbens, Basal forebrain

\section{Background}

Apathy is characterized by severe loss of motivation to participate in activities, social withdrawal and emotional indifference [1]. Apathy shares some overlapping features with depression, but can be distinguished by lack of dysphoric symptoms including sadness, hopelessness and guilt $[2,3]$. Apathy is a frequent neuropsychiatric syndrome affecting up to $92 \%$ of individuals diagnosed with Alzheimer's disease (AD) [4-6], and up to 70\% of those with Parkinson's disease (PD) [2,7-10]. Despite its prevalence, relatively little is known about the underlying neuropathology [10]. Stress exposure is an established risk factor for development of neuropsychiatric

\footnotetext{
* Correspondence: keri.martinowich@libd.org

1 Mood and Anxiety Disorders Program (MAP), National Institute of Mental Health (NIMH), National Institutes of Health (NIH), 35 Convent Drive, Building 35, Room 1C-1012, Bethesda, MD 20892-3711, USA

Full list of author information is available at the end of the article
}

symptoms [11-14], and it has been established that animal models of chronic stress cause behavioral changes similar to symptoms of depression in humans [15]. Exposure to extreme forms of chronic stress, including time spent in prisoner of war and concentration camps as well as survival of the atomic bombing, has been documented to result in an apathetic syndrome[16-19]. For example, prisoners of the Korean War have been described as having a reactive syndrome that included extreme withdrawal of involvement and a paucity of emotion, which could not be explained by depression or psychosis, but was best characterized as "apathy" [16]. Visual observation of routine animal behavior led us to hypothesize that a $6 \mathrm{hr} / \mathrm{d} />21 \mathrm{~d}$ chronic restraint stress (CRS) protocol could be useful for modeling features of apathy. The objectives of the study were to 1 ) characterize the loss of motivation and initiative in CRS-exposed animals, 2) map long-term changes in neuronal activity

\section{() Biomed Central}


in CRS-exposed animals and 3) determine whether facilitating the cholinergic system could ameliorate CRSinduced phenotypes.

\section{Methods}

\section{Animals}

We used adult (8 wk) male C57BL/6J mice (Jackson Laboratories, Bar Harbor, ME, USA) that were doublehoused in a standard mouse cage containing a metal divider splitting the cage into two separate compartments; each mouse retains an individual feeding compartment and water bottle. Mice were maintained under a 12:12 hour light-dark cycle (6:00 AM to 6:00 PM). All procedures were performed in accordance with guidelines set forth by the National Institute of Mental Health Animal Care and Use Committee in the Guide for the Care and Use of Laboratory Animals. Figure 1 gives an overview of the experimental design and groups used in the studies.

\section{Saccharin and quinine preference}

$21 \mathrm{~d}$ prior to CRS each mouse was given simultaneous access to two, dual-ball sipper-top bottles (Ancare, Bellmore, NY, USA): one with purified Milli-Q water and one containing $50 \mathrm{mg} / \mathrm{L}$ saccharine (Sigma Aldrich, St. Louis, MO, USA). Bottles were weighed and refilled every $3 \mathrm{~d}$; positions were reversed at each change to prevent side bias. After $21 \mathrm{~d}$, mice were divided into balanced groups with mice sharing a divider cage placed in the same experimental group. Individual animals with saccharin preference $<65 \%$ were excluded from the study ( $3 \%$ of total animals used). For the quinine experiment, the saccharine solution was replaced with $15 \mathrm{mg} / \mathrm{L}$ quinine hydrochloride (Sigma Aldrich, St. Louis, MO, USA) solution for $3 \mathrm{~d}$.

\section{Restraint stress}

Mice were placed in $50 \mathrm{~mL}$ plastic conical tubes with holes cut at the tips to allow for unrestricted breathing

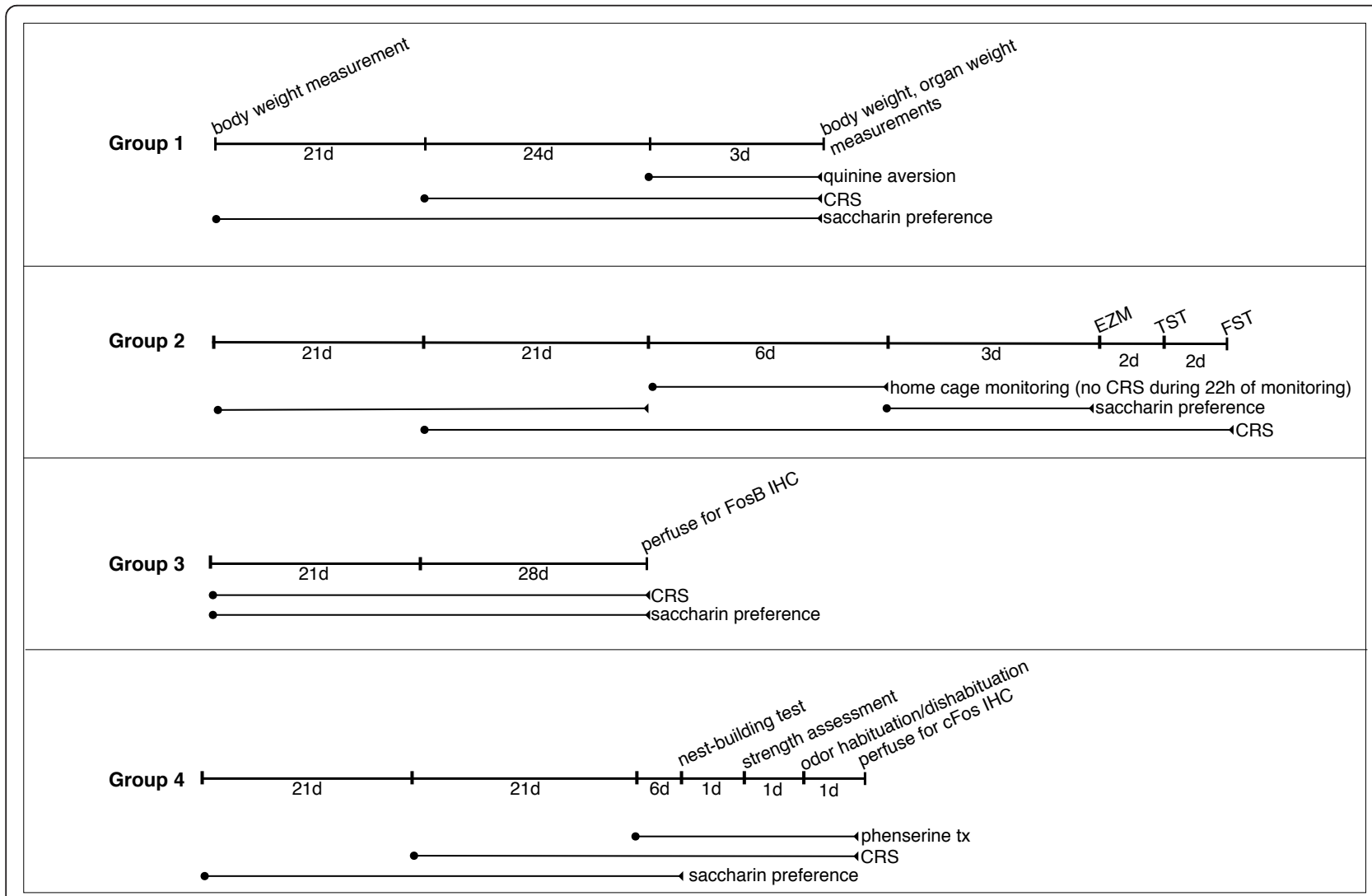

Figure 1 Experimental design. Group 1 ( $n=10$ control and $n=14$ CRS-exposed for saccharin preference and quinine aversion; body and organ weight analysis performed in $n=8$ for control versus CRS). Group 2 (for HCS, $n=8$ control and $n=9$ CRS-exposed; $n=8$ control and $n$ $=8$ CRS-exposed for TST, FST and EZM). Group 3 ( $n=6$ Control and CRS-exposed). Group 4 ( $n=12$ Control and $n=16$ CRS-exposed; CRS group further divided, $n=8$ saline and $n=8$ phenserine). For cFos immunohistochemistry (IHC) experiment control group further divided into $n$ $=6$ water exposure and $n=6$ urine exposure; $n=6$ saline/CRS/urine exposure and $n=6$ phenserine/CRS/urine exposure were analyzed. 
and gauze was inserted in the remaining space. Mice were restrained for $6 \mathrm{~h} / \mathrm{d}$ (10:00 AM-4:00 PM). All behavioral tests were performed before placement in restrainers (6 AM-10 AM).

\section{HomeCage scan}

$24 \mathrm{~h}$ after CRS, mice were placed into clean cages containing $100 \mathrm{~mL}$ sawdust bedding with food and water. Animals were monitored for $22 \mathrm{~h}$ using Sony digital cameras and CaptureStar video capturing software with infrared illumination during the dark phase. Automated video analysis of home cage behaviors was performed using HomeCageScan software (Clever Systems, Reston, VA). Behaviors were detected by utilizing information about the entire body of the animal, identifying animal body parts such as head, tail, forelimbs, hind limbs, upper/lower back, abdomen, etc., and using sequence data to automatically recognize and analyze animal behaviors in durations $>6$ frames (30 frames/s).

\section{Odor Habituation/Dishabituation}

We used a modified version of an odor discrimination task $[20,21]$ to assess effects of CRS on response to an appetitive social stimulus, i.e female estrous urine. Cotton-tipped applicators were soaked with water and fastened to the roof of each cage such that mice must rear up to sniff. Duration of sniffing was measured over a 3 min presentation. This was repeated $3 X$, then replaced by $1 \%$ imitation vanilla, and finally by urine from an estrous-stage female. Contact with the applicator with an open mouth was considered chewing, and not scored as sniffing.

\section{Nest building}

Old nesting material was removed, and two unused nestlets (paper-based nesting material compacted into white squares) [2 g/each] were placed on the cage floor. After $4 \mathrm{~h}$, nestlet material that had not been either shredded or incorporated into a nest was weighed.

\section{Tail suspension test}

Mice were suspended by their tails for 6 min using a $15 \mathrm{~cm}$ piece of lab tape wrapped around the tip of the tail. Sessions were videotaped and later scored by an observer blinded to groups. Any significant movement of the body or the limbs was considered as mobility.

\section{Forced swim test}

Transparent plexiglass cylinders, $25 \mathrm{~cm}$ tall $\times 12 \mathrm{~cm}$ diameter were filled with $30^{\circ} \mathrm{C}$ water to $\sim 21 \mathrm{~cm}$ so mice were not able to touch the floor or escape. Mice were placed in the water for $6 \mathrm{~min}$, videotaped and later analyzed with Clever Systems Forced Swim Test Scan (Clever Sys Inc., Leesburg, VA, USA). At the end of each session, mice were dried with a paper towel and returned to their home cage. Water was replaced for each trial.

\section{Elevated zero maze}

The ring-shaped platform consisted of two walled (white Plexiglas) sections separated by open sections of equal length. Each mouse was placed such that it was in an open section, directly facing a walled section. Activity was video-tracked for $5 \mathrm{~min}$ and analyzed using Clever Systems TopScan (Clever Sys Inc., Leesburg, VA, USA).

\section{Drug treatments}

Phenserine ((-)-N-phenylcarbamoyleseroline) was synthesized as a water-soluble (L)-tartrate salt (> 99.9\% optical and chemical purity)[22]. CRS-exposed mice were administered either $0.9 \%$ saline or phenserine $(1 \mathrm{mg} / \mathrm{kg}$, i.p) in the evening after the CRS session and again in the morning, $1 \mathrm{~h}$ prior to behavioral experiments. Animals within the CRS group were randomly divided into the continued CRS group and the CRS/phenserine group.

\section{Tissue preparation}

Animals were anaesthetized under isofluorane and transcardially perfused with $50 \mathrm{~mL}$ of $4 \%$ paraformaldehyde (PFA) in phosphate buffered saline (PBS). Brains were removed from the skull and postfixed overnight at $4{ }^{\circ} \mathrm{C}$ in $4 \%$ PFA/PBS, then transferred to $30 \%$ sucrose/PBS for $72 \mathrm{~h}$ for cryopreservation. Brains were mounted on a freezing stage (Physitemp Instruments, Inc., Clifton, NJ) set to $-25^{\circ} \mathrm{C}$ and coronal sections $(50 \mu \mathrm{m})$ were cut using a sliding microtome (Leica, Germany) and collected in PBS containing 0.015 M sodium azide.

\section{Immunohistochemistry}

Every 6th (prefrontal cortex and brainstem) or 12th (hypothalamus, hippocampus) section was rinsed freefloating in PBS/0.5\% Tween-20. Non-specific binding was blocked with $3 \%$ normal goat serum for $30 \mathrm{~min}$. Sections were incubated with an anti-fos B antibody directed against the N-terminus, which detects both the fulllength FosB as well as its truncated form, deltaFosB (sc48, rabbit IgG, 1:500, Santa Cruz Biotechnology, Santa Cruz, CA) or with an anti-c-fos antibody (PC38, 1:1000, Calbiochem) for $24 \mathrm{~h}$ at $4{ }^{\circ} \mathrm{C}$. Sections were rinsed in PBS/0.5\% Tween-20, incubated for $2 \mathrm{~h}$ at room temperature with biotinylated goat anti-rabbit secondary antibody (Vector Laboratories, Burlingame, CA). Endogenous peroxidase activity was blocked using $0.3 \%$ hydrogen peroxide for $30 \mathrm{~min}$. The HRP-DAB reaction was carried out using an avidin/biotin peroxidase complex (VectaStain $\mathrm{ABC}$ Kit, Vector Laboratories). Sections were incubated in $\mathrm{ABC}$ for $1 \mathrm{hr}$ and DAB-cobalt (Sigma, St. Louis MO) for $3 \mathrm{~min}$. They were then mounted on SuperFrost-Plus treated slides (Fisher Scientific, Pittsburgh, PA), air-dried, 
Nissl stained, dehydrated with alcohol rinses, cleared with CitriSolv, and coverslipped with Permount.

\section{Image analysis}

Section images were captured using a Leica DMRB light microscope equipped with a CoolSNAP digital camera and IPLab software. Cell density in the hippocampal dentate gyrus, nucleus accumbens, and cortical areas were analyzed using ImageJ. Cells in thalamic, hypothalamic, and septal nuclei were manually counted by a blinded individual. Anatomical boundaries were determined by using the Franklin and Paxinos mouse brain atlas [23].

\section{Statistical analysis}

Data are presented as group means \pm standard error of the mean (SEM). As appropriate, Student's $t$-test, oneway ANOVA with Newman Keul's post hoc or two-way ANOVA with Bonferroni post hoc were performed using GraphPad Prism 5. Statistical significance was defined as $\mathrm{p}<0.05$.

\section{Results}

\section{Motivational deficits following chronic stress}

Animals exposed to chronic stress consistently show deficits in the sucrose and/or saccharin preference test, findings which have contributed to establishing these tests as analogs of anhedonia [24-26]. A significant decrease in saccharin preference was found in CRSexposed animals $(n=14)$ when compared to control animals $(\mathrm{n}=10$ ) beginning $\sim 17 \mathrm{~d}$ after CRS initiation [ANOVA $F_{1,311}=17.33, P<0.0001$ for CRS treatment; $F_{6,311}=5.59, P<0.0001$ for time; $F_{6,311}=2.63, P=$ 0.0166 for time-CRS interaction; Bonferroni post-test, $P>0.05$ at d5, d10, d17, d25 and d31, $P<0.05$ at d38 and $P<0.01$ at $\mathrm{d} 44$ ] (Figure 2a). Directly following the last measurement for saccharin preference we changed to a 2-bottle preference test between water and mildly bitter quinine solution (Figure 1, Group 1). As expected, control mice avoided the quinine, while CRS-exposed animals drank at levels close to chance [Student's $t$-test, $P=0.0012$ ) (Figure $2 \mathrm{~b}$ ). To validate physiological markers of chronic stress we measured total body weight as well as weights of the adrenals, thymus and testes. Body weights of non-stressed animals $(\mathrm{n}=8)$ significantly increased over the experiment while body weights of CRS-exposed animals $(\mathrm{n}=8)$ did not [ANOVA $F_{1,28}=$ 28.79, $P<0.0001$ for CRS treatment; $F_{1,28}=30.79, P<$ 0.0001 for time; $F_{1,28}=30.54, P<0.0001$ for time-CRS interaction; Bonferroni post-test, $P<0.001$ for Control versus CRS after CRS exposure] (Figure 2c). As expected, there was a significant increase in adrenal weight $\left[F_{7,6}=3.097\right.$, Student's $t$-test $\left.P=0.0022\right]$ (Figure 1d) and significant decreases in both thymus $\left[F_{7,7}=\right.$ 2.186, Student's $t$-test $P<0.0001$ ] (Figure 2e) and testes
$\left[F_{7,7}=1.452\right.$, Student's $t$-test $\left.P=0.0001\right]$ (Figure 2f) weight in CRS-exposed animals.

The decrease in initiative to both approach an appetitive stimulus and avoid an aversive stimulus indicates a potential deficit in motivation. Chronic stress models have frequently been used to model symptoms of anhedonia, and these models consistently reveal related deficits in other depressive- and anxiety-like behaviors. We tested CRSexposed animals $(n=8)$ as compared to control animals $(\mathrm{n}=8)$ in two measures of behavioral despair, the tail suspension test (TST) and the forced swim test (FST). We observed no difference in immobility times in the TST [ $F_{7,7}=1.385$, Student's $t$-test $\left.P=0.8802\right]$ (Figure 3a), but saw a significant decrease in immobility times in the FST $\left[F_{7,7}=5.994\right.$, Student's $t$-test $\left.P<0.0001\right]$ (Figure 3b). This result is likely confounded by decreased body-weights in CRS-exposed animals (Figure 2c). We also tested CRSexposed animals in the elevated zero maze (EZM) where an increase in time spent in the open portion of the maze indicates decreased anxiety-like behavior. Control and CRS-exposed animals spent similar amounts of times in the open portions of the maze $\left[F_{7,7}=3.854\right.$, Student's $t$-test $P=0.1749$ ] (Figure 3c).

\section{Changes in home cage behavior following chronic stress}

To better understand the full range of effects of CRS on normal home cage activity, we utilized automated behavioral recognition software, HomeCage Scan (CleverSys Inc., Reston, VA, USA), to monitor home cage activity for $22 \mathrm{~h}$ (Figure 1, Group2). We began recording $24 \mathrm{~h}$ following CRS, and analyzed the following behaviors: rear up, hang cuddled, drink, eat, groom, sleep, chew, twitch, sniff, remain low and walk slowly (software definitions in Table 1). Prior to experimentation, accuracy of the software in analyzing all behaviors was verified and calibrated to experienced hand-scorers.

Our analysis revealed significant differences between control and CRS-exposed mice in total incidence as well as in diurnal patterns of numerous behaviors. CRSexposed mice spent significantly less total time rearing, hanging cuddled, sniffing and walking slowly, but showed no difference in total time spent grooming drinking, eating, sleeping, twitching, chewing and remaining low (Table 2). In the first $41 / 2$ hours prior to dark cycle onset, CRS-exposed mice spent less time rearing up (Figure 4a), hanging cuddled (Figure 4b), sniffing (Figure 4c), remaining low (Figure 4k) and walking slowly (Figure 4d). However, they spent more time drinking (Figure 4f) and resting (Figure 4h). It should be noted that differences in behavior between the control and CRS-exposed groups at experiment onset could reflect differences in novelty response since the cage was changed before beginning the recording. As expected there was a spike in most active behaviors (Figure 4a-d, f, g, j, k) at dark cycle initiation and a sharp 


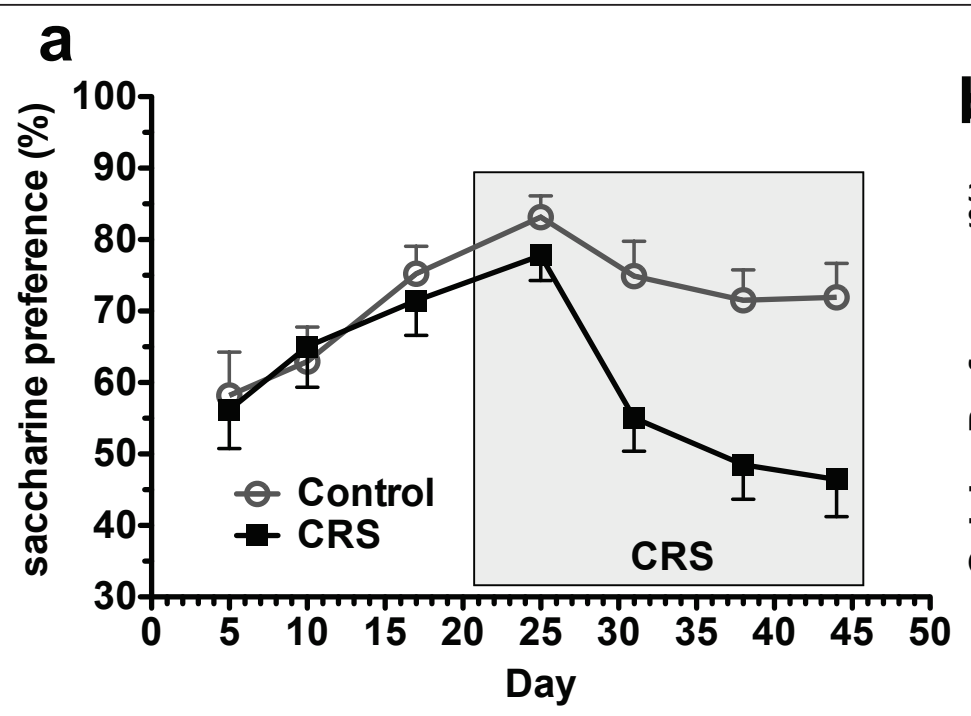

b

C

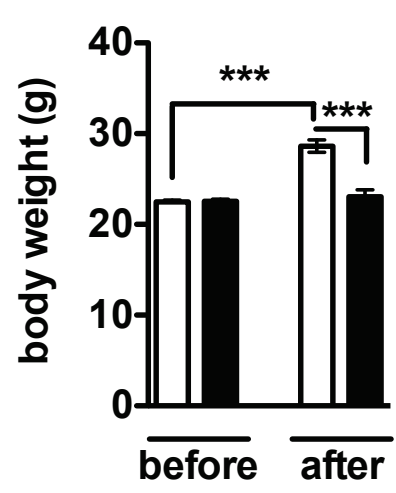

d
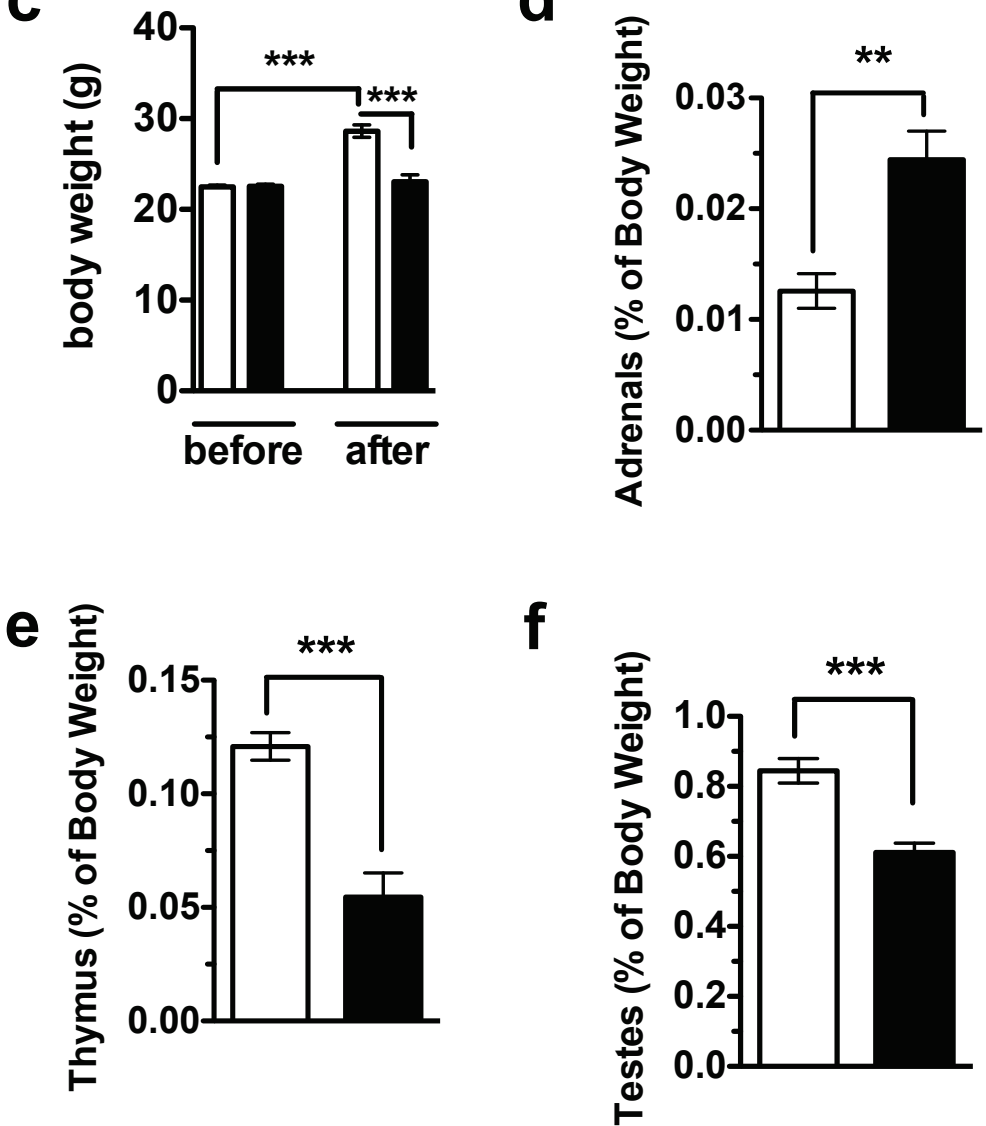

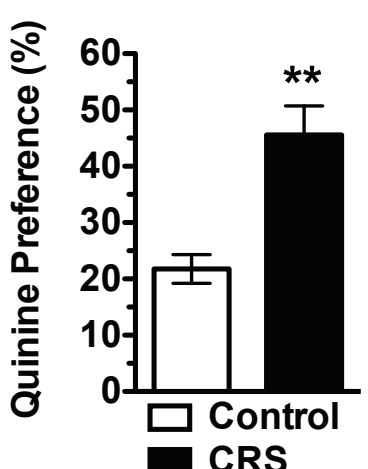

CRS

Figure 2 CRS-exposed mice exhibit a decreased appetitive response, and fail to avoid a mildly aversive stimulus. (a) Preference ratios for saccharin versus water in control and CRS-exposed mice in Group 1 (see Figure 1). Shaded area denotes CRS exposure. (b) Preference ratio for quinine versus water in control and CRS-exposed mice. (c) Control animals gain significantly more weight than CRS-exposed animals over the course of the experiment, while CRS animals do not gain a significant amount of weight and weigh significantly less than controls after CRSexposure. (d) Increased adrenal weight in CRS-exposed animals; presented as \% of total body weight. CRS exposure leads to decreased thymus weight. (f) CRS exposure leads to a decreased testes weight. Results here and in subsequent figures are reported as mean $\pm \operatorname{SEM}$; ${ }^{*}=p<0.05$, $*^{* *}=p<0.01$ and $^{* *}=p<0.001$. 


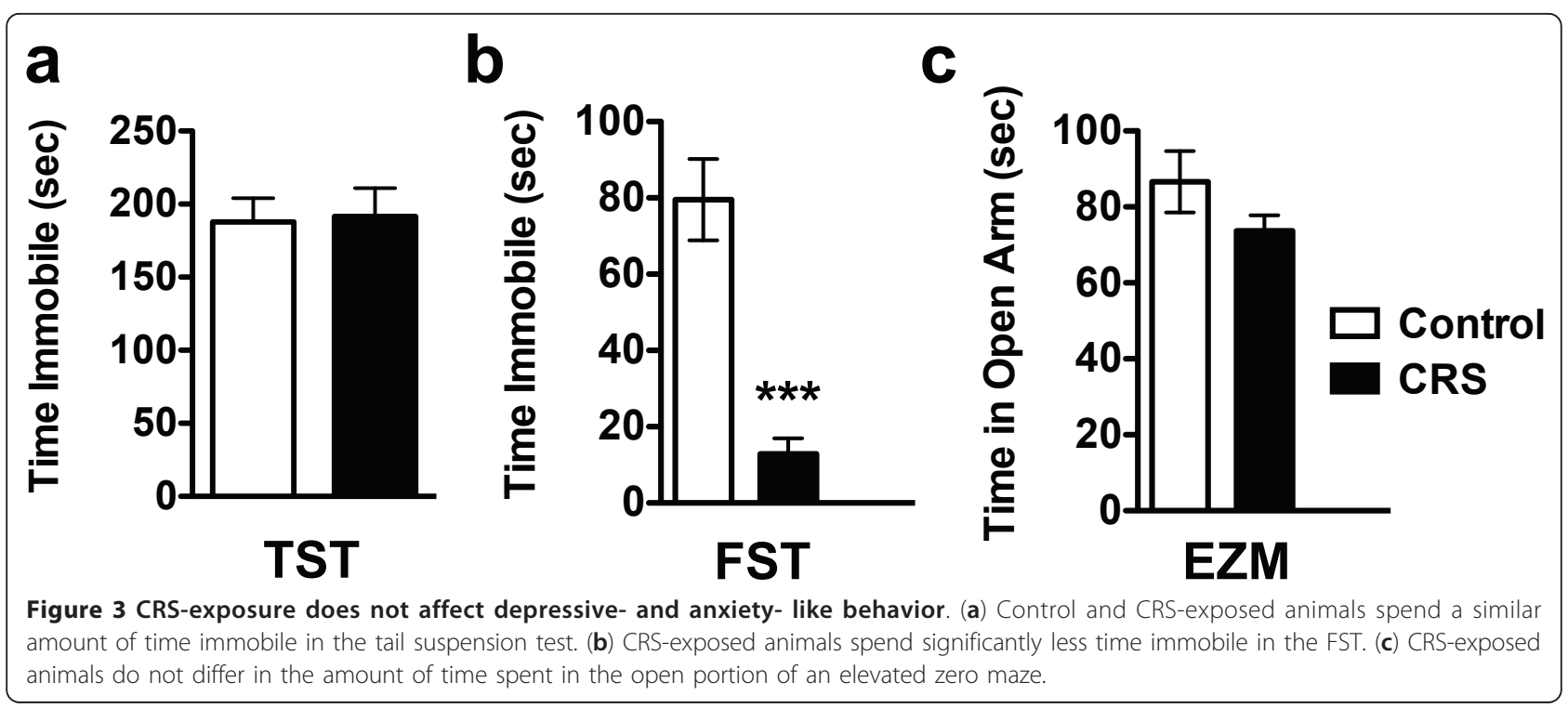

drop in inactive behaviors (Figure $4 \mathrm{~h}, \mathrm{i}$ ) in both groups. At this time, control and CRS-exposed animals were similar in sniffing (Figure 4c), walking slowly (Figure 4d) and remaining low (Figure $4 \mathrm{k}$ ). However, the CRS-exposed group showed lower levels of rearing (Figure 4a) and hanging behavior (Figure 4b), but higher levels of drinking (Figure 4f), eating (Figure 4g) and chewing (Figure 4j) during the first $\sim 4$ hours of the dark phase. During the shift from dark to light (hours 15-18) CRS-exposed mice spent significantly more time resting than control mice (Figure 4h). As opposed to control mice, whose active behaviors showed a short, final peak right at the dark to light transition, CRS-exposed animals showed no peak in rearing (Figure 4a), hanging (Figure 4b), eating (Figure 4g), chewing (Figure 4j), walking slowly (Figure 4d), sniffing (Figure 4c) and remaining low (Figure 4k).

To examine overall trends in behavior, we created a behavior-array analysis grid displaying fold increases and decreases between control and CRS-exposed mice (Figure 5). Each box represents an individual behavior and time point within the experiment. The intensity of color for each box represents the magnitude of behavioral change between control and CRS-exposed mice. Overall, CRS-exposed mice displayed significant decreases in exploratory behaviors such as rear-up and sniff, as well as in locomotor behaviors including walk slowly, remain low, and hang cuddled for several hours directly prior to the onset of the dark cycle and before the onset of the

Table 1 Software definitions for scoring HomeCage Scan behaviors

\begin{tabular}{|c|c|}
\hline Behavior & Software Definition \\
\hline Rear Up & $\begin{array}{l}\text { Begins with the mouse lifting its front paws off the ground and standing on its hind legs. Rearing ends when the mouse comes } \\
\text { back down and places one front paw back on the ground. Rearing may also include "partially reared" in which the mouse hunches } \\
\text { its back and its front paws are off the ground, and is about halfway from being in the fully stretched, completely reared position. }\end{array}$ \\
\hline $\begin{array}{l}\text { Hang } \\
\text { Cuddled }\end{array}$ & Both forelimbs and hindlegs are above the midpoint between the floor and the top of the cage. \\
\hline Drink & $\begin{array}{l}\text { Behavior starts when mouth is at level with the drinking spout. Behavior ends when mouth withdraws from the drinking spout. } \\
\text { Sniffing behaviors directly before drinking are scored as drinking. }\end{array}$ \\
\hline Eat & $\begin{array}{l}\text { Snout is in the plane of the food compartment with minimal body and head movements. "Sniff" and "eat" are differentiated by the } \\
\text { total time the snout remains in the food bin, with "sniff" being significantly less duration in the compartment. However, if the mouse } \\
\text { sniffs directly before eating, the sniff behavior is scored as eating. }\end{array}$ \\
\hline Groom & $\begin{array}{l}\text { Mouse uses front paws to clean itself by rubbing over body and face in circular movements. Repetitive paw movements over a } \\
\text { certain period of time are scored as groom. }\end{array}$ \\
\hline Sleep & $\begin{array}{l}\text { A minimum of } 30 \mathrm{~s} \text { of no significant movement of the mouse while it is in a non-rearing and non-hanging position is scored as } \\
\text { sleep. }\end{array}$ \\
\hline Twitch & Any movement occurring during sleep \\
\hline Sniff & Body of mouse is stationary, but snout moves in a bobbing fashion. Scored as an exploratory behavior. \\
\hline Remain Low & Prolonged inactivity of the mouse that is not scored by the software as any other behavior. \\
\hline Walk Slowly & Mouse is moving across the cage and at least three legs are propelling it forward \\
\hline
\end{tabular}


Table 2 Home-cage behavior analysis array of control versus CRS-exposed mice

\begin{tabular}{|c|c|c|c|c|c|c|}
\hline \multirow[b]{2}{*}{ Behavior } & \multicolumn{2}{|c|}{ Control } & \multicolumn{2}{|c|}{ CRS } & \multirow[b]{2}{*}{$F$ value } & \multirow[b]{2}{*}{$P$ value } \\
\hline & Mean (s) & SEM & Mean (s) & SEM & & \\
\hline Rear Up & 81.08 & 9.21 & 28.99 & 4.26 & 3.12 & $<0.0001$ \\
\hline Hang Cuddled & 268.7 & 18.13 & 118.7 & 25.23 & 2.9 & 0.01 \\
\hline Sniff & 2783 & 230.2 & 1717 & 221.1 & 1.38 & 0.01 \\
\hline Walk Slowly & 1918 & 143.4 & 1414 & 137.1 & 1.37 & 0.03 \\
\hline Groom & 8820 & 771 & 10050 & 858.4 & 1.86 & 0.34 \\
\hline Drink & 185.6 & 24.18 & 334.1 & 69.94 & 12.55 & 0.12 \\
\hline Eat & 4451 & 503 & 4773 & 976.5 & 5.65 & 0.8 \\
\hline Sleep & 27560 & 883 & 31670 & 1799 & 6.23 & 0.1 \\
\hline Twitch & 667.2 & 75.62 & 776.3 & 58.71 & 1.11 & 0.27 \\
\hline Chew & 930.4 & 139.9 & 1330 & 184.1 & 2.6 & 0.14 \\
\hline Remain Low & 12120 & 810 & 11120 & 598.6 & 1.22 & 0.33 \\
\hline
\end{tabular}

light cycle (Figure 5), suggesting a decrease in initiation of non-essential activities. However, directly prior to dark cycle onset, inactive behaviors such as twitch and rest increased in the CRS mice.

\section{Neuronal activity mapping}

We used FosB immunohistochemistry to analyze neuronal activity patterns in control and CRS-exposed animals. Animals were killed $24 \mathrm{~h}$ following the last session of CRS and brains processed for FosB immunoreactivity (Figure 1, Group 3). The antibody used detects both full-length FosB as well as truncated deltaFosB, which gradually accumulates due to its high stability and long half-life. A recent report showed that in CRS-exposed rats $(1 \mathrm{~h} / \mathrm{d} / 10 \mathrm{~d})$, deltaFosB is the predominant Fos family protein induced and that the 35-37 kDa deltaFosB isoform is the only Fos family protein that remains elevated $24 \mathrm{~h}$ after the final stress exposure [27]. In agreement with a previous study [27], CRS-exposed mice $(6 \mathrm{hr} / \mathrm{d} / 28 \mathrm{~d})$ showed significant increases in FosB immunoreactivity in the medial septum (MS)/nucleus of the vertical limb of the diagonal band (vDB) and the lateral septum (LS) (Table 3, Figure 6). Differing from this study [27], we observed significant increases in FosB immunoreactivity in hypothalamic regions including the arcuate nuclei and the paraventricular nucleus (PVN), but no differences in the prelimbic cortex (PrL), the infra-limbic cortex (IL) or the nucleus accumbens (NAcc). The differences between our results and those in previous studies may be explained by species and strain differences or from differences in CRS duration and protocol $[27,28]$.

\section{Effects of cholinergic facilitation on motivation and apathetic behavior}

DeltaFosB accumulation in the MS/vDB, one of the major basal forebrain cholinergic nuclei, suggests that this area undergoes significant changes in gene transcription and neuronal activity after CRS. This data, coupled with reports that treatment with acetylcholinesterase inhibitors (AChE-I) leads to remediation of apathetic behavior[10,29], led us to ask whether the CRS-induced behavioral deficits could be rescued by facilitating cholinergic signaling.

We administered phenserine, a centrally active and potent AChE-I, $21 \mathrm{~d}$ after initiating CRS. Phenserine was administered $2 \mathrm{x} / \mathrm{d} / 6 \mathrm{~d}$ in accord with its anticholinesterase half-life of $8.25 \mathrm{~h}$ before beginning behavioral analysis (Figure 1, Group 4) [30]. Preference ratios for Control animals were $74.5 \pm 7.2$ and preference ratios for CRS-exposed animals were $50.4 \pm 4.7$ prior to the phenserine study. Saline-injected CRS-exposed animals showed no improvement in saccharin preference, but CRS-exposed animals administered phenserine increased preference by $\sim 13 \%$ over stress-induced depressed levels [ANOVA $F_{2,21}=6.505, P=0.007$; Newman-Keuls Multiple Comparisons for Control vs CRS $P>0.05$, for Control vs CRS/Phenserine $P<0.05$ and for CRS versus CRS/Phenserine $P<0.01$ ] (Figure 7a). We next looked at the effect of phenserine on the motivation levels of CRS-exposed animals in a nest-building paradigm. Existing nests and nesting materials were removed, and animals were provided new nesting material. After $4 \mathrm{~h}$, unused nesting material was measured. CRS-exposed animals showed significantly decreased motivation in nest building as determined by incorporation of less nestlet material, but phenserine treatment led to a significant improvement [ANOVA $F_{2,21}=11.00, P=$ 0.0001; Newman-Keuls Multiple Comparisons for Control vs CRS $P<0.001$, for Control vs CRS/Phenserine $P<0.05$ and for CRS versus CRS/Phenserine $P<0.05$ ] (Figure $7 \mathrm{~b}$ ). We ruled out the possibility that the decreased nest-building could be a result of weakness in the CRS-exposed animals by performing a wire hang test to check for muscle strength [ANOVA $F_{2,21}=$ 1.172, $P=0.3291$ ] (Figure 7c).

To determine whether loss of motivational drive in the saccharin preference test transfers to an alternative appetitive stimulus, we measured the time spent sniffing on urine from a female estrous mouse in a modified odor habituation/dishabituation test. We first measured time spent sniffing a Q-tip dipped in water upon its initial presentation and then habituation to the smell on the 2nd and 3rd presentations. Next, we determined whether the animal showed normal dishabituation in response to presentation of a novel vanilla scent and then habituation to this scent on the 2 nd and 3rd presentations. Lastly, we introduced female estrous urine and measured dishabituation and then habituation. Both control and CRS-exposed mice showed normal habituation and dishabituation curves in response to the 3 stimuli (Figure 7d). Animals 


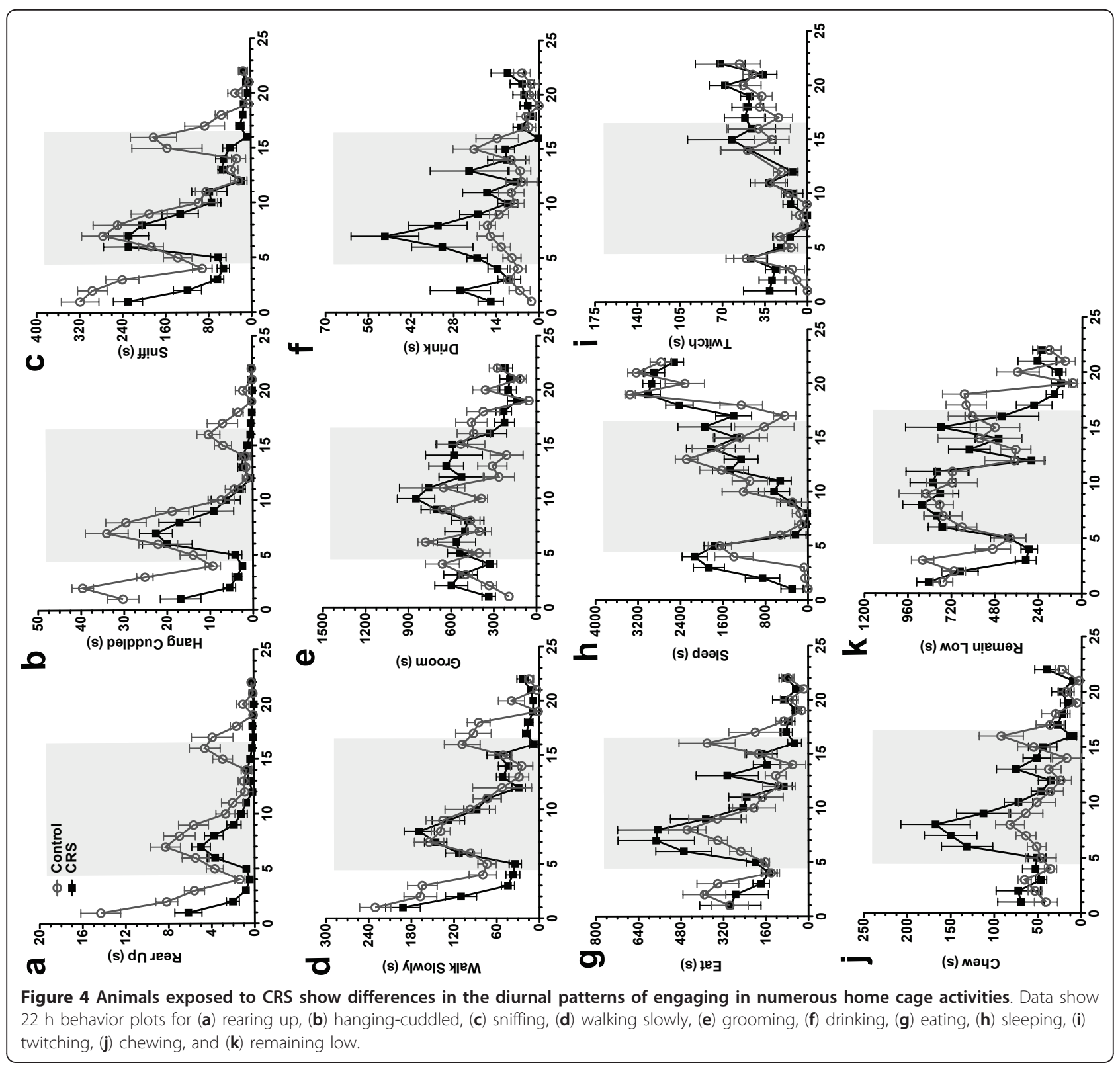

exposed to CRS spent slightly less overall time sniffing on water [ANOVA $F_{2,21}=4.101, P=0.0314$; Newman-Keuls Multiple Comparisons for Control vs CRS $P<0.05$, for Control vs CRS/Phenserine $P>0.05$ and for CRS versus CRS/Phenserine $P>0.05$ ] (Figure 7e), no difference in time spent sniffing on vanilla [ANOVA $F_{2,21}=5.46, P=$ 0.0149; Newman-Keuls Multiple Comparisons for Control vs CRS $P>0.05$, for Control vs CRS/Phenserine $P<0.05$ and for CRS versus CRS/Phenserine $P>0.05$ ] (Figure 7f), and significantly less time sniffing on estrous urine [ANOVA $F_{2,21}=24.03, P<0.0001$; Newman-Keuls Multiple Comparisons for Control vs CRS $P<0.001$, for Control vs CRS/Phenserine $P<0.01$ and for CRS versus CRS/ Phenserine $P<0.01$ ] (Figure 7g).
To better understand the brain regions phenserine may act on to mediate its behavioral effects in CRS-exposed animals, we used c-fos immunohistochemistry to examine neuronal activation patterns in response to presentation of estrous urine. For this experiment, animals were divided into 4 groups: saline-injected/non-CRS exposed animals that sniffed on a Q-tip dipped in water, saline-injected/ non-CRS exposed animals that sniffed on a Q-tip dipped in estrous urine, saline-injected/CRS exposed animals that sniffed on a Q-tip dipped in estrous urine and phenserineinjected/CRS-exposed animals that sniffed on Q-tip dipped in estrous urine. Animals were allowed to sniff on the Q-tip for $3 \mathrm{~min}$ and killed $2 \mathrm{~h}$ later for c-fos immunohistochemistry. In non-stressed, saline-injected animals 


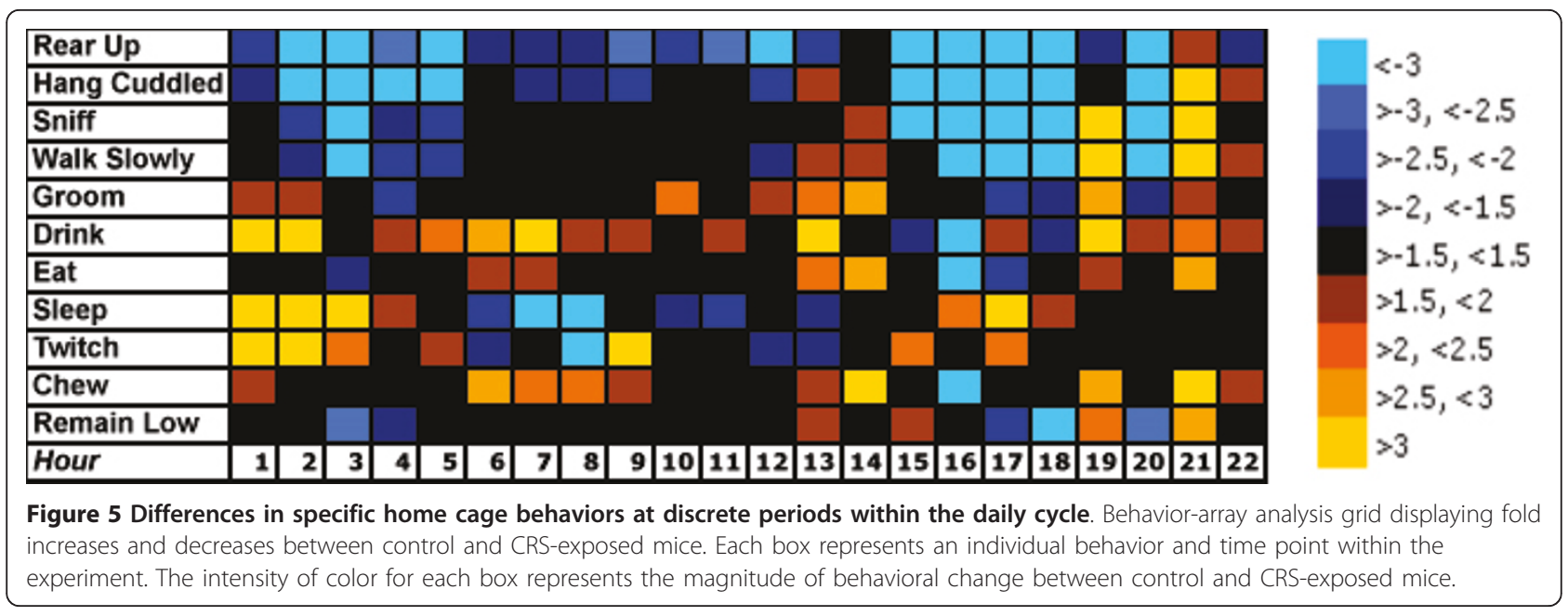

$(n=6)$, sniffing on estrous urine (hatched bars) as opposed to water (white bars) increases c-fos immunoreactivity in numerous brain regions including the medial preoptic area (MPO), LS, MS, NAcc and PrL (Figure 8a, b, c, $\mathrm{d}$ and 8e). CRS-exposed animals that were injected with saline $(n=6)$ (black bars) did not show the increase in cfos immunoreactivity in the MPO, LS, MS, NAcc and PrL (Figure 8a, b, c, d and 8e) after sniffing on estrous urine. However, phenserine administration in CRS-exposed animals $(n=6)$ was capable of fully rescuing the response to estrous in the NAcc (Figure 8d) and partially rescuing the response in the MS (Figure 8c). ANOVA and post-hoc statistics for Figure 8 are provided in the accompanying Table 4.

\section{Discussion}

A major objective of this study was to characterize CRSinduced deficits in motivational drive. As expected CRS- exposed animals lost their preference for saccharin, but also failed to avoid a bitter quinine solution (Figure 2a, b). A similar phenomenon has been reported in rhesus monkeys following maternal deprivation [31]. This study proposed that in addition to producing anhedonia, some chronic stress paradigms may decrease motivation for appetitive stimuli in general [31]. Deficits in the sucrose and saccharin preference tests have been reliably used as measures of anhedonia [24-26], which is defined as the inability to experience pleasure in previously enjoyable activities such as eating, exercising, socializing and sex [32-34]. The saccharin preference deficit coupled with the lack of quinine aversion may also indicate apathy, a lack of interest in surroundings, social withdrawal and loss of motivation and initiative $[35,36]$. Apathy, on its own, or when co-morbid with depression poses a challenge to clinicians due to their overlapping symptomatology and frequent co-occurrence [3]. Identifying apathy requires

Table 3 deltaFosB immunoreactivity in control versus CRS-exposed mice

\begin{tabular}{|c|c|c|c|c|c|}
\hline \multirow[t]{2}{*}{ Brain Region } & \multirow{2}{*}{$\begin{array}{r}\text { Control } \\
\text { Mean (Cells/pixel) }\end{array}$} & \multirow{2}{*}{$\frac{\text { CRS }}{\text { Mean (Cells/pixel) }}$} & \multicolumn{2}{|c|}{ Fold Difference } & \multirow[b]{2}{*}{$P$ Value } \\
\hline & & & CRS vs Control & F Value & \\
\hline Dentate Gyrus & 0 & 0 & 1.2891 & 1.533 & 0.11 \\
\hline Nucleus Accumbens & 0 & 0 & 1.4205 & 2.061 & 0.07 \\
\hline Prelimbic Cortex & 0 & 0 & 1.4308 & 8.433 & 0.05 \\
\hline Infralimbic Cortex & 0 & 0 & 1.0169 & 1.328 & 0.93 \\
\hline Cingulate Cortex & 0 & 0 & 1.0033 & 2.134 & 0.99 \\
\hline \multirow[t]{2}{*}{ Visual Cortex } & 0 & 0 & 1.1538 & 1.295 & 0.25 \\
\hline & Mean (cells counted) & Mean (cells counted) & & & \\
\hline Medial Septum/vDB & 25.67 & 52.83 & 2.0580 & 1.794 & 0.01 \\
\hline Lateral Septum & 568.7 & 1564 & 2.7501 & 2.510 & $<0.0001$ \\
\hline PVA & 164.8 & 243 & 1.4745 & 2.718 & 0.22 \\
\hline PVN & 34.17 & 125.3 & 3.6670 & 15.590 & 0 \\
\hline Arcuate & 10 & 52.17 & 5.2170 & 12.710 & 0 \\
\hline SCN & 5.83 & 2.5 & 0.4286 & 3.628 & 0.26 \\
\hline
\end{tabular}



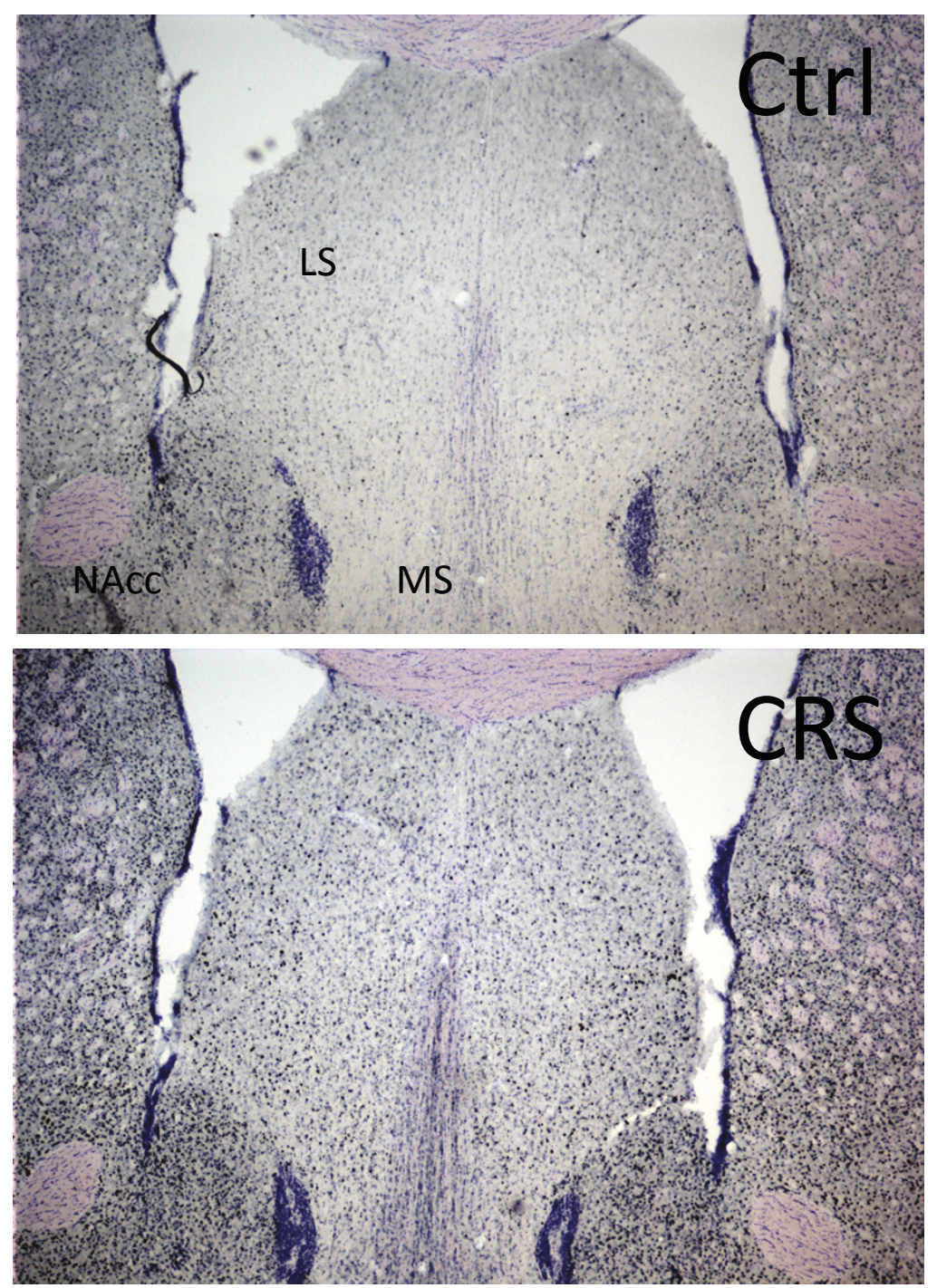

Figure 6 Changes in deltaFosB immunoreactivity following CRS exposure. Representative image showing increased deltaFosB immunoreactivity in the medial septum (MS) and lateral septum (LS) after exposure to CRS.

differentiation between loss of initiation versus loss of ability and emotional indifference versus a primary mood disturbance [7]. Modeling apathy is important since it does not respond similarly to treatment options for anhedonia $[37,38]$. Accordingly, despite their overlapping symptomatology, there is accumulating evidence that apathy and anhedonia may have different underlying alterations in brain circuits [3,39].

We show that loss of motivational drive in CRS-exposed animals in the saccharin preference test can transfer to a decrease in motivation for an alternative appetitive stimulus. First, we showed that CRS-exposed animals showed normal habituation and dishabituation to three different odors, confirming intact olfactory senses (Figure 7d). However, we observed a significant decrease in interest for estrous urine (Figure 7g), suggesting that these animals exhibit deficits in motivational drive. CRS-exposed animals also show lack of motivation in a nest-building paradigm $[35,36]$ and decreases in home-cage exploratory behaviors. For example, we saw significant differences in total time spent rearing up, hanging cuddled and sniffing (Table 2), and in patterns of diurnal activity. Since alterations in sleep and circadian rhythms play a critical role in the pathophysiology of numerous neuropsychiatric disorders $[33,40,41]$, the ability to model circadian alterations is a useful experimental tool.

It has been suggested that apathy may reflect an interaction between cholinergic deficiency and subsequent neurological changes in limbic regions [42]. Thus, we asked whether deltaFosB accumulation in the MS/vDB, 


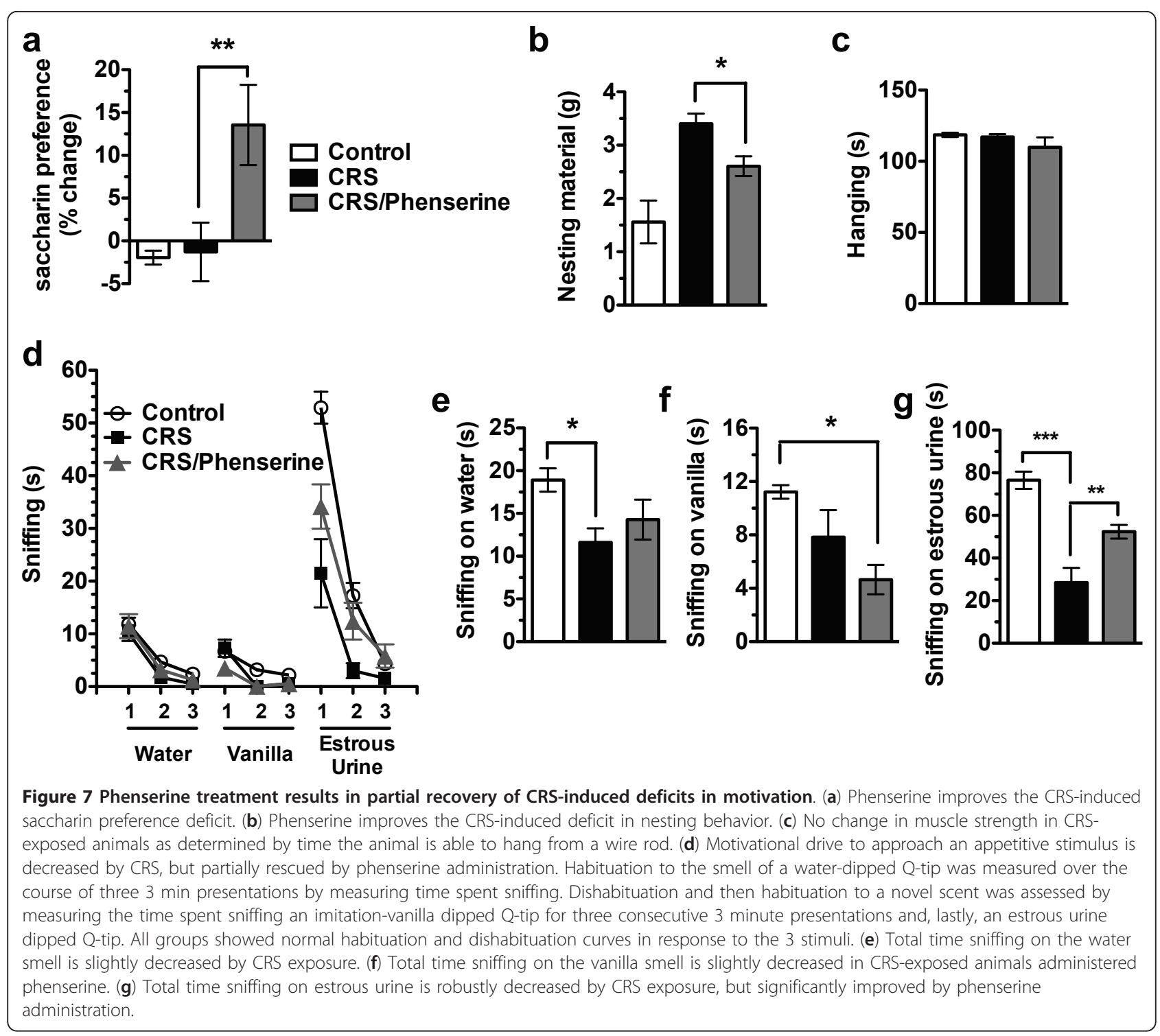

which constitutes the major cholinergic projection to the hippocampal formation, cingulate cortex and the hypothalamus [29] could be influencing cholinergic signaling. AChE-I treatment reduces incidence of apathy and improves functioning in patients who present with cholinergic disturbances in limbic and paralimbic cortices $[10,29]$, and restoration of function in these brain regions may underlie the behavioral response to AChEIs $[9,43]$. In $A D$, functional loss is thought to be a consequence of neuronal loss in cholinergic nuclei, and it has previously been reported that CRS can result in hippocampal atrophy [44]. However, it appears that cholinergic function in our model may be altered via changes resulting from alterations in plasticity as opposed to neuronal loss because levels of the cholinergic cell marker $\mathrm{p} 75^{\mathrm{NTR}}$ are unchanged between control and CRS- exposed animals and there are no appreciable changes in regional volume between control and CRS-exposed animals (KM and RJS, unpublished observations).

It is also possible that the behavioral effects of phenserine in our model result from activation of cholinergic interneurons in areas implicated in motivation and reward. For example, it has been shown that the AChEIs galantamine and donepezil lead to increased dopamine release in NAcc $[45,46]$. Control animals show a robust increase in immediate early gene activation in the NAcc after being exposed to a motivating stimulus, i.e. estrous urine (Figure 8d), but this increase is lost in CRS-exposed animals. However, phenserine administration rescued this deficit, suggesting that cholinergic facilitation may restore dopaminergic function in the CRS-exposed NAcc. This restorative function could 


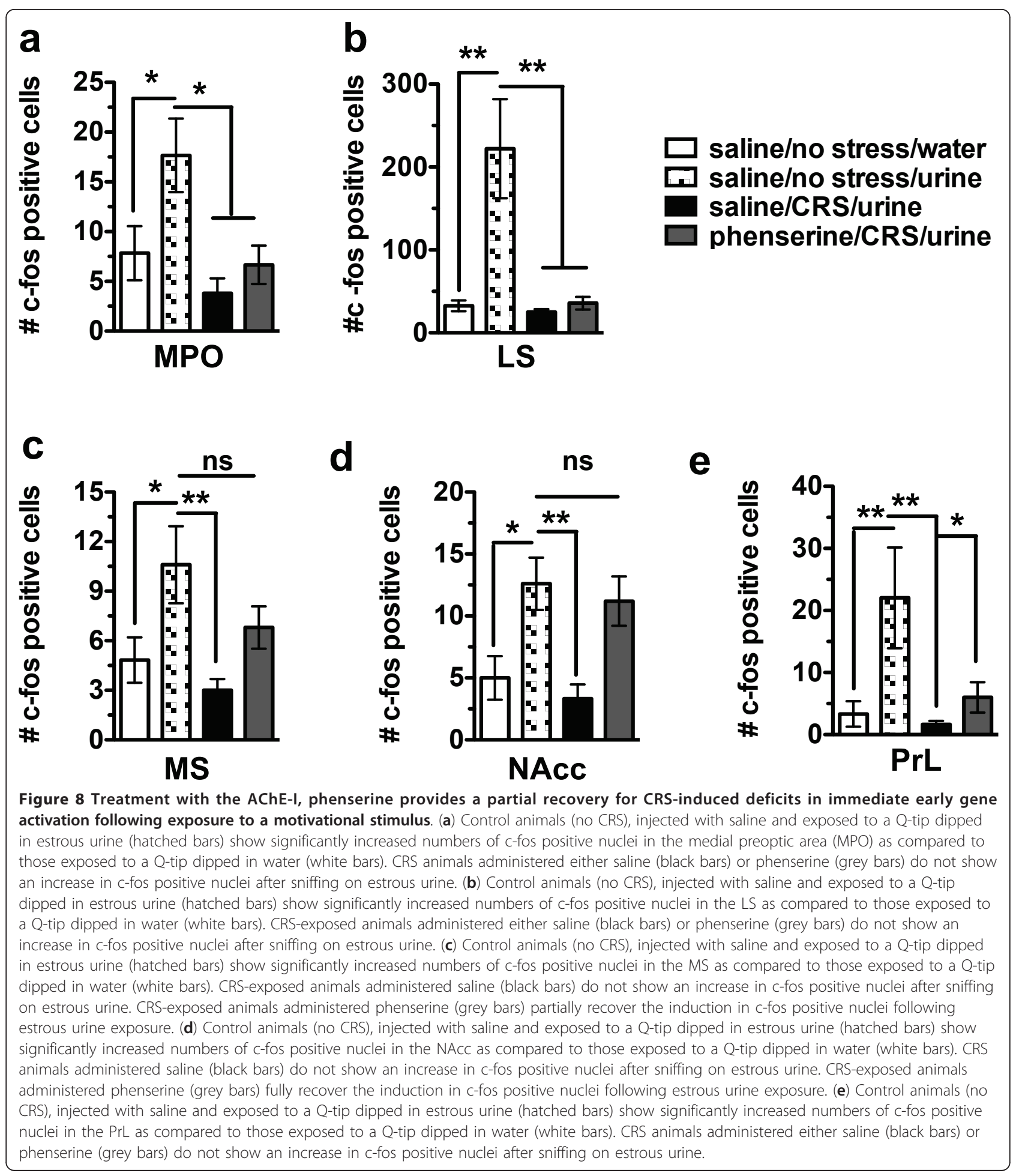

contribute to phenserine's role in behavioral rescue of motivational drive in CRS-exposed animals (Figure 7a, b, d).

The focus of the experiments with phenserine was to determine whether an anticholinesterase had utility in reversing selected CRS-induced phenotypes rather than determining the effect of the drug in a naïve population. However, it remains a caveat of our studies that our study did not include a control group to look at the effects of phenserine in a non-CRS exposed population. 
Table 4 ANOVA table for statistics in Figure 8

\begin{tabular}{lllllllll}
\hline \multicolumn{7}{c}{ Newman-Keul's post hoc } \\
\hline Brain Region & $\boldsymbol{F}$ value & $\boldsymbol{P}$ value & white vs hatched & white vs black & white vs gray & hatched vs black & hatched vs gray & black vs hatched \\
\hline MPO & 5.03 & $P<0.05$ & $P>0.05$ & $P>0.05$ & $P<0.05$ & $P<0.05$ & $P<0.05$ & $P<0.05$ \\
\hline MPO & 5.03 & $P<0.05$ & $P>0.05$ & $P>0.05$ & $P<0.05$ & $P<0.05$ & $P<0.05$ & $P<0.05$ \\
\hline LS & 8.76 & $P<0.01$ & $P>0.05$ & $P>0.05$ & $P<0.01$ & $P<0.01$ & $P<0.001$ & $P<0.01$ \\
\hline MS & 4.82 & $P<0.05$ & $P>0.05$ & $P>0.05$ & $P<0.01$ & $P<0.01$ & $P>0.05$ & $P<0.01$ \\
\hline NACC & 6.8 & $P<0.05$ & $P>0.05$ & $P<0.05$ & $P<0.01$ & $P<0.01$ & $P>0.05$ & $P<0.01$ \\
\hline
\end{tabular}

Thus, it is possible that the effects of phenserine may not be limited to animals exposed to CRS, but may also have similar effects on a control population.

\section{Conclusions}

This CRS protocol resulted in behaviors reflecting motivational loss and diminished emotional responsiveness as well as changes in deltaFos B accumulation in brain regions that could affect normal cholinergic signaling. Facilitating the cholinergic system results in partial rescue of CRS-induced impairments to initiation and motivational drive. Our study provides support for further study of utilizing AChE-Is and cholinergic mimetics in neuropsychiatric symptoms of motivational loss and apathetic behavior.

\section{Abbreviations}

CRS: Chronic restraint stress; AD: Alzheimer's disorder; TST: Tail suspension test; FST: Forced swim test; EZM: Elevated zero maze; MS: Medial septum; VDB: Vertical limb of the diagonal band; LS: Lateral septum; PVN: Paraventricular nucleus; NAcc: Nucleus accumbens; ANOVA: Analysis of variance; MPO: Medial preoptic area; PrL: Prelimbic area

\section{Acknowledgements}

Funding for this study was provided by the National Institute of Mental Health (NIMH) and the National Institute on Aging (NIA) Intramural Programs.

\section{Author details}

${ }^{1}$ Mood and Anxiety Disorders Program (MAP), National Institute of Mental Health (NIMH), National Institutes of Health (NIH), 35 Convent Drive, Building 35, Room 1C-1012, Bethesda, MD 20892-3711, USA. ${ }^{2}$ Laboratory of Neuroscience, Section on Drug Design and Development, National Institute on Aging (NIA), National Institutes of Health (NIH), Bethesda, MD 20892-3711, USA. ${ }^{3}$ Lieber Institute for Brain Development, Johns Hopkins Medical Campus, 855 N. Wolfe Street, Suite 300, Baltimore, MD 21205 USA. ${ }^{4}$ Johnson \& Johnson Pharmaceutical Research and Development, 1125 TrentonHarbourton Road, Titusville, NJ, 08560 USA.

\section{Authors' contributions}

KM designed the studies, performed research, analyzed data and wrote the manuscript. KMC performed research and analyzed data. RJS designed the studies, performed research and analyzed data. MH performed research and analyzed data. NHG designed the studies and synthesized phenserine. HKM designed the studies. All authors read and approved the final manuscript.

\section{Competing interests}

Keri Martinowich, Kathleen M. Cardinale, Michael Hsu, Nigel H. Greig and Robert J. Schloesser report no biomedical financial interests or potential conflicts of interest. Husseini K. Manji is a paid employee of Johnson and Johnson Pharmaceutical Research.
Received: 20 June 2011 Accepted: 20 March 2012

Published: 20 March 2012

\section{References}

1. Marin RS: Apathy: a neuropsychiatric syndrome. J Neuropsychiatry Clin Neurosci 1991, 3:243-254.

2. Landes AM, Sperry SD, Strauss ME, Geldmacher DS: Apathy in Alzheimer's disease. J Am Geriatr Soc 2001, 49:1700-1707.

3. Levy ML, Cummings JL, Fairbanks LA, Masterman D, Miller BL, Craig AH, Paulsen JS, Litvan I: Apathy is not depression. J Neuropsychiatry Clin Neurosci 1998, 10:314-319.

4. Onyike CU, Sheppard JM, Tschanz JT, Norton MC, Green RC, Steinberg M, Welsh-Bohmer KA, Breitner JC, Lyketsos CG: Epidemiology of apathy in older adults: the Cache County Study. Am J Geriatr Psychiatry 2007, 15:365-375.

5. Craig D, Mirakhur A, Hart DJ, Mcllroy SP, Passmore AP: A cross-sectional study of neuropsychiatric symptoms in 435 patients with Alzheimer's disease. Am J Geriatr Psychiatry 2005, 13:460-468.

6. Lyketsos CG, Lopez O, Jones B, Fitzpatrick AL, Breitner J, DeKosky S: Prevalence of neuropsychiatric symptoms in dementia and mild cognitive impairment: results from the cardiovascular health study. JAMA 2002, 288:1475-1483.

7. Boyle PA, Malloy PF: Treating apathy in Alzheimer's disease. Dement Geriatr Cogn Disord 2004, 17:91-99.

8. Drijgers RL, Aalten P, Winogrodzka A, Verhey FR, Leentjens AF: Pharmacological treatment of apathy in neurodegenerative diseases: a systematic review. Dement Geriatr Cogn Disord 2009, 28:13-22.

9. Levy ML, Cummings JL, Kahn-Rose R: Neuropsychiatric symptoms and cholinergic therapy for Alzheimer's disease. Gerontology 1999, 45(Suppl 1):15-22.

10. Mega MS, Masterman DM, O'Connor SM, Barclay TR, Cummings JL: The spectrum of behavioral responses to cholinesterase inhibitor therapy in Alzheimer disease. Arch Neurol 1999, 56:1388-1393.

11. Matthews K, Robbins TW: Early experience as a determinant of adult behavioural responses to reward: the effects of repeated maternal separation in the rat. Neurosci Biobehav Rev 2003, 27:45-55.

12. Paykel ES: Stress and affective disorders in humans. Semin Clin Neuropsychiatry 2001, 6:4-11.

13. Hammen C, Davila J, Brown G, Ellicott A, Gitlin M: Psychiatric history and stress: predictors of severity of unipolar depression. J Abnorm Psychol 1992, 101:45-52.

14. Cui XJ, Vaillant GE: Antecedents and consequences of negative life events in adulthood: a longitudinal study. Am J Psychiatry 1996, 153:21-26.

15. Anisman $\mathrm{H}$, Matheson $\mathrm{K}$ : Stress, depression, and anhedonia: caveats concerning animal models. Neurosci Biobehav Rev 2005, 29:525-546.

16. Strassman $H D$, Thaler $M B$, Schein $E H: A$ prisoner of war syndrome: apathy as a reaction to severe stress. Am J Psychiatry 1956, 112:998-1003.

17. Ohta $Y$, Mine $M$, Wakasugi $M$, Yoshimine $E$, Himuro $Y$, Yoneda $M$, Yamaguchi S, Mikita A, Morikawa T: Psychological effect of the Nagasaki atomic bombing on survivors after half a century. Psychiatry Clin Neurosci 2000, 54:97-103.

18. Nardini JE: Survival factors in American prisoners of war of the Japanese. Am J Psychiatry 1952, 109:241-248.

19. Tas J: Psychial disorders among inmates of concentration camps and repatriates. Psychiatr Q 1951, 25:679-690. 
20. Yang M, Crawley JN: Simple behavioral assessment of mouse olfaction. Curr Protoc Neurosci 2009, Chapter 8, Unit 824.

21. Malkesman O, Scattoni ML, Paredes D, Tragon T, Pearson B, Shaltiel G, Chen G, Crawley JN, Manji HK: The female urine sniffing test: a novel approach for assessing reward-seeking behavior in rodents. Biol Psychiatry 2010, 67:864-871.

22. Yu Q, Holloway HW, Flippen-Anderson JL, Hoffman B, Brossi A, Greig NH: Methyl analogues of the experimental Alzheimer drug phenserine: synthesis and structure/activity relationships for acetyl- and butyrylcholinesterase inhibitory action. J Med Chem 2001, 44:4062-4071.

23. Franklin KBJ, Paxinos G: The Mouse Brain in Stereotaxic Coordinates Academic Press; 1997.

24. Willner P: Chronic mild stress (CMS) revisited: consistency and behavioural-neurobiological concordance in the effects of CMS. Neuropsychobiology 2005, 52:90-110.

25. Moreau JL: Validation of an animal model of anhedonia, a major symptom of depression. Encephale 1997, 23:280-289.

26. Muscat R, Willner P: Suppression of sucrose drinking by chronic mild unpredictable stress: a methodological analysis. Neurosci Biobehav Rev 1992, 16:507-517.

27. Perrotti LI, Hadeishi Y, Ulery PG, Barrot M, Monteggia L, Duman RS, Nestler EJ: Induction of deltaFosB in reward-related brain structures after chronic stress. J Neurosci 2004, 24:10594-10602.

28. Nikulina EM, Arrillaga-Romany I, Miczek KA, Hammer RP Jr: Long-lasting alteration in mesocorticolimbic structures after repeated social defeat stress in rats: time course of mu-opioid receptor mRNA and FosB/ DeltaFosB immunoreactivity. Eur J Neurosci 2008, 27:2272-2284.

29. Cummings JL: Cholinesterase inhibitors: A new class of psychotropic compounds. Am J Psychiatry 2000, 157:4-15.

30. Greig NH, Sambamurti K, Yu QS, Brossi A, Bruinsma GB, Lahiri DK: An overview of phenserine tartrate, a novel acetylcholinesterase inhibitor for the treatment of Alzheimer's disease. Curr Alzheimer Res 2005, 2:281-290.

31. Paul IA, English JA, Halaris A: Sucrose and quinine intake by maternallydeprived and control rhesus monkeys. Behav Brain Res 2000, 112:127-134.

32. Nelson JC, Charney DS: The symptoms of major depressive illness. Am J Psychiatry 1981, 138:1-13.

33. Hasler G, Drevets WC, Manji HK, Charney DS: Discovering endophenotypes for major depression. Neuropsychopharmacology 2004, 29:1765-1781.

34. Fawcett J, Clark DC, Scheftner WA, Gibbons RD: Assessing anhedonia in psychiatric patients. Arch Gen Psychiatry 1983, 40:79-84.

35. Chung JA, Cummings JL: Neurobehavioral and neuropsychiatric symptoms in Alzheimer's disease: characteristics and treatment. Neurol Clin 2000, 18:829-846.

36. Frisoni GB, Rozzini L, Gozzetti A, Binetti G, Zanetti O, Bianchetti A, Trabucchi M, Cummings JL: Behavioral syndromes in Alzheimer's disease: description and correlates. Dement Geriatr Cogn Disord 1999, 10:130-138.

37. Barnhart WJ, Makela EH, Latocha MJ: SSRI-induced apathy syndrome: a clinical review. J Psychiatr Pract 2004, 10:196-199.

38. Wongpakaran N, van Reekum R, Wongpakaran T, Clarke D: Selective serotonin reuptake inhibitor use associates with apathy among depressed elderly: a case-control study. Ann Gen Psychiatry 2007, 6:7

39. Andersson S, Krogstad JM, Finset A: Apathy and depressed mood in acquired brain damage: relationship to lesion localization and psychophysiological reactivity. Psychol Med 1999, 29:447-456.

40. Bunney WE, Bunney BG: Molecular clock genes in man and lower animals: possible implications for circadian abnormalities in depression. Neuropsychopharmacology 2000, 22:335-345.

41. Nieoullon A, Bentue-Ferrer D, Bordet R, Tsolaki M, Forstl H: Importance of circadian rhythmicity in the cholinergic treatment of Alzheimer's disease: focus on galantamine*. Curr Med Res Opin 2008, 24:3357-3367.

42. Cummings JL, Back C: The cholinergic hypothesis of neuropsychiatric symptoms in Alzheimer's disease. Am J Geriatr Psychiatry 1998, 6:S64-78.

43. Cummings JL, Kaufer D: Neuropsychiatric aspects of Alzheimer's disease: the cholinergic hypothesis revisited. Neurology 1996, 47:876-883.

44. Watanabe Y, Gould E, McEwen BS: Stress induces atrophy of apical dendrites of hippocampal CA3 pyramidal neurons. Brain Res 1992, 588:341-345.

45. Zhang L, Zhou FM, Dani JA: Cholinergic drugs for Alzheimer's disease enhance in vitro dopamine release. Mol Pharmacol 2004, 66:538-544.
46. Ligorio M, Descarries L, Warren RA: Cholinergic innervation and thalamic input in rat nucleus accumbens. J Chem Neuroanat 2009, 37:33-45.

doi:10.1186/1744-9081-8-15

Cite this article as: Martinowich et al:: Acetylcholinesterase inhibition ameliorates deficits in motivational drive. Behavioral and Brain Functions 2012 8:15.

\section{Submit your next manuscript to BioMed Central and take full advantage of:}

- Convenient online submission

- Thorough peer review

- No space constraints or color figure charges

- Immediate publication on acceptance

- Inclusion in PubMed, CAS, Scopus and Google Scholar

- Research which is freely available for redistribution

Submit your manuscript at www.biomedcentral.com/submit
Biomed Central 